\title{
Pericardial Strip versus Ring Annuloplasty for Repair of Functional Tricuspid Regurgitation
}

\author{
Husain Hamza Jabbad, Ahmed Abdelrahman Elassal, Osama Saber Eldib* \\ Cardiothoracic Surgery Department (KAUH), Zagazig University, Zagazig, Egypt \\ Email: u saber@yahoo.com
}

Received 8 October 2014; revised 10 November 2014; accepted 10 December 2014

Copyright (C) 2014 by authors and Scientific Research Publishing Inc.

This work is licensed under the Creative Commons Attribution International License (CC BY). http://creativecommons.org/licenses/by/4.0/

c) (i) Open Access

\begin{abstract}
Background: Functional tricuspid regurgitation is a challenge regarding indications for repair and proper surgical technique. Aim of the study: We reviewed our midterm results of tricuspid valve repair for functional regurgitation comparing pericardial strip versus ring annuloplasties. Patients and methods: From January 2008 to December 2013, we operated 59 patients (male:female, 41:18, with a mean age of $34 \pm 14$ years) for functional tricuspid regurgitation. Tricuspid annuloplasty was done using pericardial strip in 39 patients and ring in 20 patients. Concomitant procedures were mitral valve replacement in $66 \%$ of patients, aortic valve replacement in $5 \%$ and double valve replacement in $29 \%$. Clinical and echocardiographic data were collected. Results: Preoperative characteristics of the two groups were similar regarding age, percentage of female patients, New York Heart Association functional class and pulmonary artery pressure. More patients with preoperative right ventricular dysfunction were found in pericardial annuloplasty group although this was not statistically significant $(13$ versus $5 ; P=0.52)$. Operative times were similar in both groups. We had one mortality case $(1.69 \%)$ due to low cardiac output in the pericardial group. Postoperative complications included reexploration for bleeding in one patient and chronic heart failure in another patient. The average follow up period was 3 years and it was complete in $\mathbf{1 0 0 \%}$ of patients. Postoperative freedom from recurrent moderate tricuspid regurgitation was $\mathbf{9 0 \%}$ in both groups. Conclusion: Pericardial strip annuloplasty is a simple, inexpensive, reproducible and efficient technique that has comparable results to ring annuloplasty.
\end{abstract}

\section{Keywords}

Pericardial Strip Annuloplasty, Tricuspid Ring Annuloplasty, Functional Tricuspid Regurgitation

\footnotetext{
${ }^{*}$ Corresponding author.
} 


\section{Introduction}

Functional tricuspid regurgitation is most commonly caused by left sided valvular lesion or myocardial disease [1]. Management of tricuspid regurgitation (TR) is usually carried out in conjunction with other valvular lesions. If not corrected properly, residual TR will have negative impact on functional state and survival [2].

Repair methods such as De Vega suture has good early results, however late recurrence of TR is significant. Different types of rings were developed for improving the results [3].

Here we present our experience in tricuspid valve repair using strip of autologous pericardium in comparison to rigid annuloplasty ring.

\section{Patients and Methods}

This study was conducted under a protocol approved by institution research ethics committee in King Abdul Aziz University Hospital (KAUH).

From January 2008 to December 2013, 59 patients underwent tricuspid annuloplasty for functional TR as part of their cardiac surgical procedure at KAUH. Patients were identified and preoperative, operative, and postoperative variables were retrieved from the prospective KAUH Cardiac Surgery Database. Autologous pericardial annuloplasty was performed in 39 (66\%) patients. Ring annuloplasty was performed in 20 (34\%) patients. Of those undergoing ring annuloplasty, 17 (85\%) had Carpentier-Edwards semirigid ring (Edwards Life Sciences), and 3 (15\%) had Carbomedics Annuloflex ring (Sulzer Carbomedics, Inc, Austin, Tex). Annuloplasty type depended on surgeon preference.

\section{Operative Techniques}

All annuloplasties were performed during concomitant aortic and/or mitral valve surgery with the aorta clamped. Ring annuloplasty was performed by standard operative techniques. For autologous pericardial annuloplasty, we used the technique developed by Chang et al. [4]. We started by harvesting and preparing an autologous pericardial strip (8 to $10 \mathrm{~cm}$ in length, 5 to $8 \mathrm{~mm}$ in width). The smooth surface was kept upwards and was sutured to the tricuspid annulus with interrupted mattress sutures of 2 - 0 Ethibond suture (Ethicon, Inc, Somerville, NJ). We started from the posteroinferior aspect of the septal leaflet to the anterior septal commissure. The interval between sutures was 2 - $3 \mathrm{~mm}$ in the autologous pericardial strip and $5-6 \mathrm{~mm}$ in the tricuspid annulus. By this way the tricuspid annulus could be shortened (Figure 1). After the procedure, we measured the annular diameter using a valve sizer.

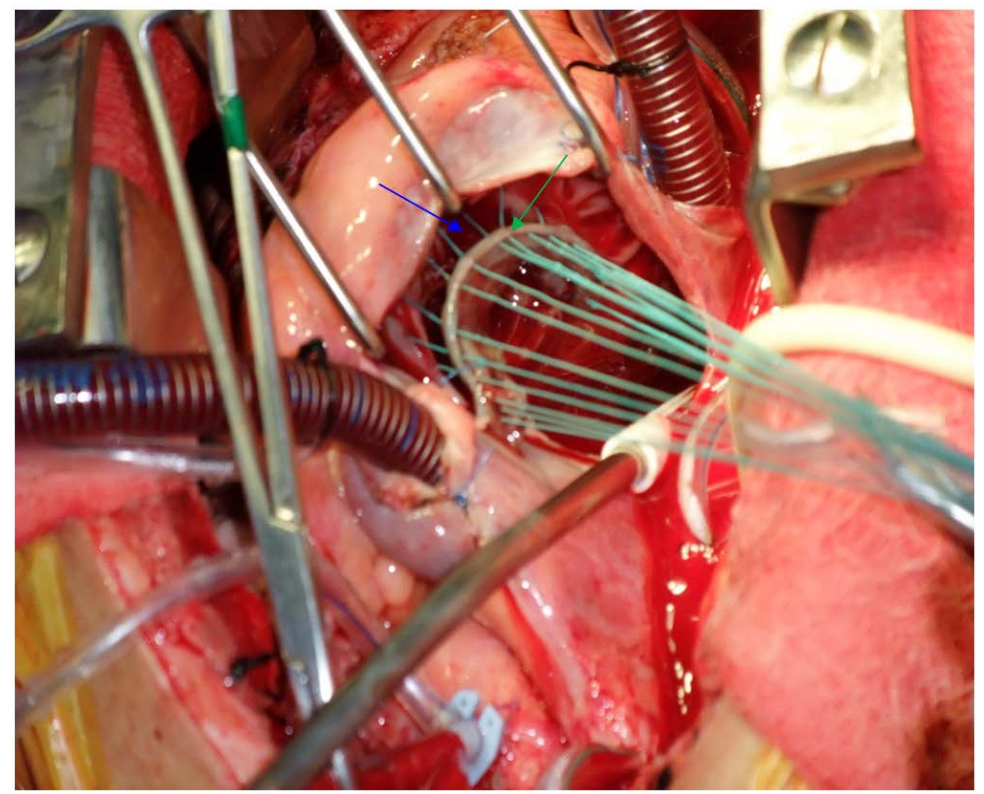

Figure 1. Intraoperative view showing pericardial strip (green arrow) before fixing it to tricuspid annulus (blue arrow). 
In all patients, intraoperative assessment of the valve was done either by direct injection of normal saline solution $0.9 \%$ in the right ventricle (RV) through the valve in arrested heart or suctioning the coronary sinus in beating heart to evaluate any regurgitated flow from right ventricle to right atrium. Intraoperative transesophageal echocardiography was used to confirm adequacy of the repair.

Concomitant mitral valve surgery was performed in $66 \%$ of patients, and aortic valve surgery in $5 \%$. Triple valve surgery was performed in $29 \%$ patients.

\section{Follow-Up}

The status of all patients was assessed cross-sectionally in 2011. Follow-up data (vital status, functional status, and/or postoperative echocardiograms) were obtained for all patients. Echocardiographic reports were reviewed from the KAUH Health Care clinical database or obtained from the patient's cardiologist. Mean follow-up time was 3 years.

\section{Statistical Analysis}

The data were entered and analyzed using the statistical package for social sciences (SPSS Inc, Chicago, IL, USA), version 16.00. The quantitative data were presented in the form of mean, standard deviation and range, and were compared using independent t-test. Chi-square test or Fisher's exact test were used to compare qualitative data where appropriate. We considered statistical significance when $\mathrm{P}$ value $<0.05$ and confidential interval of 95 percent.

\section{Results}

Preoperative patient characteristics are shown in (Table 1).

Patients were operated for moderate or severe functional TR. It was associated with left sided valve pathology in all patients. Rheumatic mitral valve pathology was found in $95 \%$ of cases. No previous cardiac operations were performed. Female gender accounts for $30 \%$ of patients. Patients repaired by pericardial ring showed higher proportion of RV failure manifestations (jaundice, neck vein congestion, ascites, enlarged liver and pitting edema) although this was not statistically significant $(\mathrm{P}=0.52)$.

\section{Operative Outcome}

We had one case of early mortality (defined as within 30 days of surgery or during the same hospitalization). This patient was 20 years, male patient operated for mitral valve replacement (MVR) and aortic valve replacement (AVR) with pericardial annuloplasty for TR. He was suffering from sickle cell anemia, renal failure (on dialysis) and EF: 40\%. He died on postoperative day 11 because of low cardiac output. No late deaths were recorded. Regarding postoperative complications one patient operated for MVR and pericardial annuloplasty of TV was reexplored for bleeding that proved to be nonsurgical. Ten days later he was operated for clotted left sided hemothorax and was discharged in stable condition. The second complication was among ring annuloplasty group that was a 31 years female patient operated for mitral and tricuspid valve lesions. It was difficult to wean her from mechanical ventilation and inotropic support. She was discharged home but still under antifailure medications. No ring related complications were reported e.g. dehiscence, embolism, or endocarditis. No significantly statistical difference was found between the two groups regarding aortic clamping or bypass times (Table 2).

\section{Assessment of Repair}

Transthoracic echocardiography combined with color Doppler flow study were used to assess TR grade pre- and postoperatively. Median time of echocardiographic assessment was 1 year. TR was graded as 0 for no regurgitation, 1 for mild, 2 for moderate, 3 for moderate to severe, and 4 for severe.

The degree of TR was markedly improved in the two groups with no statistically significant difference. TR grade $\leq 1$ was achieved in $90 \%$ of patients in both groups.

At the end of follow up, TR $\geq$ grade 2 was found in 4 patients in PA group and 1 patient in RA group (Table 3). 
Table 1. Preoperative characteristics.

\begin{tabular}{|c|c|c|c|c|}
\hline Pre op Variable & Over all $(n=50)$ & PA $(n=39)$ & RA $(n=20)$ & $P$ value \\
\hline Age (mean \pm SD) & $34 \pm 14(16-69)$ & $34 \pm 14(16-65)$ & $35 \pm 15(16-69)$ & 0.96 \\
\hline Female sex & 18 & 10 & 8 & 0.27 \\
\hline \multicolumn{5}{|l|}{ Preop NYHA class } \\
\hline VI & 4 & 3 & 1 & 1 \\
\hline III & 34 & 24 & 10 & 0.41 \\
\hline II & 21 & 12 & 9 & 0.29 \\
\hline RV dysfunction & 18 & 13 & 5 & 0.52 \\
\hline EF mean \pm SD & $0.551 \pm 0.851$ & $0.543 \pm 0.834$ & $0.557 \pm 0.902$ & 0.95 \\
\hline$\leq 0.4$ & 3 & 2 & 1 & 1 \\
\hline \multicolumn{5}{|l|}{ TR } \\
\hline Moderate & 17 & 10 & 7 & 0.22 \\
\hline Moderate to severe & 25 & 17 & 8 & 0.55 \\
\hline Severe & 17 & 12 & 5 & 0.76 \\
\hline \multicolumn{5}{|l|}{ TR } \\
\hline +mitral disease & 39 & 26 & 13 & 0.90 \\
\hline +aortic disease & 3 & 2 & 1 & 1 \\
\hline +double & 17 & 11 & 6 & 0.89 \\
\hline \multicolumn{5}{|l|}{ PH } \\
\hline Mean \pm SD & $76.98 \pm 14.73$ & $75.59 \pm 13.12$ & $79.70 \pm 17.50$ & 0.31 \\
\hline
\end{tabular}

PA: Pericardial annuloplasty; RA: Ring annuloplasty; NYHA: New York Heart Association; RV: right ventricle; EF: ejection fraction; PH: pulmonary hypertension.

Table 2. Operative data.

\begin{tabular}{cccc}
\hline Variable & PA & RA & P value \\
\hline Tricuspid + mitral & 26 & 13 & 0.89 \\
+aortic & 2 & 1 & 0.98 \\
+double & 11 & 6 & 0.64 \\
Bypass time (min): & & & 0.40 \\
Tricuspid + mitral & $92.80 \pm 7.75$ & $90.54 \pm 10.57$ & 0.12 \\
$\quad$ +aortic & $105 \pm 7.78$ & $77 \pm 0$ & 0.15 \\
+double & $124.45 \pm 12.65$ & $125.67 \pm 5.0$ & 0.78 \\
Clamping time (min): & & & 0.84 \\
Tricuspid + mitral & $66.50 \pm 5.73$ & $66.38 \pm 5.85$ & 0.38 \\
+aortic & $99.50 \pm 4.2$ & $69 \pm 0$ & $99.67 \pm 4.80$ \\
+double & $96.18 \pm 8.18$ &
\end{tabular}

P value $\geq 0.05$.... Not significant.

Table 3. Postoperative variables.

\begin{tabular}{|c|c|c|c|c|c|}
\hline \multirow{2}{*}{ Variable } & \multicolumn{2}{|c|}{ PA } & \multicolumn{2}{|c|}{ RA } & \multirow{2}{*}{$P$ value } \\
\hline & No. & $\%$ & No. & $\%$ & \\
\hline RV failure & 2 & 5.13 & 1 & 5 & 1 \\
\hline \multicolumn{6}{|l|}{ Early TR } \\
\hline Mild & 18 & 46.15 & 6 & 30 & 0.24 \\
\hline Moderate & 2 & 5.13 & 2 & 10 & 0.59 \\
\hline Severe & 1 & 2.56 & 0 & 0 & 1 \\
\hline \multicolumn{6}{|l|}{ Midterm TR } \\
\hline Mild & 18 & 46.15 & 5 & 25 & 0.16 \\
\hline Moderate & 3 & 7.70 & 1 & 5 & 1 \\
\hline Severe & 1 & 2.56 & 0 & 0 & 1 \\
\hline
\end{tabular}




\section{Discussion}

Tricuspid valve repair for functional TR is challenging regarding indications and optimum surgical techniques [5]. According to AHA/ACC guidelines, intervention for functional TR is indicated in patients with severe TR who are undergoing surgery for left sided valvular lesions (Class I, level evidence C). TV repair can benefit patients with mild or moderate TR with either tricuspid annular dilatation or prior evidence of right heart failure (Class IIa, level evidence B) [6]. The importance of considering repair based on TV annular diameter irrespective of the degree of TR was demonstrated in many studies [7] [8]. Management options for functional TR include conservative treatment, repair and replacement.

Conservative management of TR is justified in mild TR provided that the annulus and valvular structure are within normal [9]. Reluctance to interfere was previously based on a concept that functional TR will improve after dealing with mitral valve pathology and pulmonary hypertension. Nevertheless, postoperative residual TR may not regress and thus increases morbidity and mortality [10]. It is important to achieve satisfactory repair of TR from the start since redo operations for isolated TR have high mortality rate [11]. Adequate physiologic and anatomic correction influences long term results of the repair. Tricuspid valve replacement requires high level of anticoagulation and has serious complications and higher rate of mortality [12] [13]. Repair methods were developed to avoid these problems. De Vega repair is simple, easy and has good early results. However, inadequate reduction of annular dilatation leads to significant long term recurrence of TR [14]. Many studies were conducted to compare De Vega stitch versus ring annuloplasty. Recently, Khorsandi M et al. reviewed such studies and found that there is good evidence to support ring annuloplasty over conventional De Vega suture annuloplasty in terms of recurrent TR and survival [15]. Non ring repair subjects the tricuspid annulus to the increased PAP and RVSP causing its dilatation with worsening TR. [16] Annuloplasty with CE ring has the advantage of correcting annular dilatation and reducing recurrence. However, it impairs tricuspid annular contraction that participates in RV function [4]. In 1998, Chang et al. developed the technique of tricuspid repair using autologous pericardium. They found it flexible, easy, resistant to infection, and without cost. They performed conventional suture annuloplasty (De Vega or Kay) in 117 patients and autologous pericardial strip annuloplasty in 217 patients and compared between the two groups regarding long-term recurrence-free survival. They found pericardial strip annuloplasty better. Their results of pericardial annuloplasty were comparable to ring annuloplasty used in other studies [4]. Since 2008, annuloplasty was our preferred method to correct functional TR especially that most of our patients are rheumatic and have severe pulmonary hypertension. First we used ring for repair and later the use of pericardial strip was more frequent. We had 10\% recurrent TR in the pericardial group which is comparable to that of Chang et al. (11.1\%). We applied the same surgical technique described by Chang et al. for pericardial strip annuloplasty but regarding estimating the length of pericardial strip we used the obturator sizer as recommended by Al Ebrahim and Alassal [17]. Although, our study was conducted on adult patients, we believe that pericardial strip annuloplasty is suitable also for children with the advantage of flexibility permitting growth. Results of tricuspid valve surgery in terms of functional status, ventricular performance and pulmonary vascular resistance are greatly dependent on appropriate management of left sided valvular lesions [18]. We mainly concentrated in our postoperative results on assessing tricuspid valve competence. To our knowledge our study is the only one that compares pericardial strip annuloplasty versus ring annuloplasty. We did not find statistically significant difference between the two groups regarding operative outcome, functional status, or recurrent TR. However, it has some limitations. First of all, the number of the cases is small and the number of patients operated with ring annuloplasty is fewer than the pericardial group. Second, it is a retrospective non randomized midterm study. Third, we were not including patients with mild TR and significant annular dilatation or PH. And lastly, if we could assess RV function and tricuspid annular motion in a future study it might show difference that supports our hypothesis of physiological advantage of pericardial annuloplasty.

\section{Conclusion}

In conclusion, pericardial strip annuloplasty is a simple, reproducible, cost effective technique that has comparable results to ring annuloplasty.

\section{Acknowledgements}

We wish to thank Dr. Meaad Khayat for her efforts in statistical assistance. 


\section{References}

[1] Badano, L.P., Muraru, D. and Enriquez-Sarano, M. (2013) Assessment of Functional Tricuspid Regurgitation. European Heart Journal, 34, 1875-1885. http://dx.doi.org/10.1093/eurheartj/ehs474

[2] Nath, J., Foster, E. and Heidenreich, P.A. (2004) Impact of Tricuspid Regurgitation on Long-Term Survival. Journal of the American College of Cardiology, 43, 405-409. http://dx.doi.org/10.1016/j.jacc.2003.09.036

[3] Rivera, R., Duran, E. and Ajuria, M. (1985) Carpentier’s Flexible Ring versus De Vega’s Annuloplasty. A Prospective Randomized Study. The Journal of Thoracic and Cardiovascular Surgery, 89, 196-203.

[4] Chang, B.C., Song, S.W., Lee, S., Yoo, K.J., Kang, M.S. and Chung, N. (2008) Eight-Year Outcomes of Tricuspid Annuloplasty Using Autologous Pericardial Strip for Functional Tricuspid Regurgitation. Annals of Thoracic Surgery, 86, 1485-1493. http://dx.doi.org/10.1016/j.athoracsur.2008.07.007

[5] Raja, S.G. and Dreyfus, G.D. (2010) Basis for Intervention on Functional Tricuspid Regurgitation. Seminars in Thoracic and Cardiovascular Surgery, 22, 79-83.

[6] Nishimura, R.A., Otto, C.M., Sorajja, P., Sundt, T.M., Bonow, R.O., Carabello, B.A., Erwin III, J.P., et al. (2014) AHA/ACC Guideline for the Management of Patients with Valvular Heart Disease A Report of the American College of Cardiology/American Heart Association Task Force on Practice Guidelines. Journal of the American College of Cardiology, 63, e57-e185. http://dx.doi.org/10.1016/j.jacc.2014.02.536

[7] Chan, V., Burwash, I.G., Lam, B.K., Auyeung, T., Tran, A., Mesana, T.G. and Ruel, M. (2009) Clinical and Echocardiographic Impact of Functional Tricuspid Regurgitation Repair at the Time of Mitral Valve Replacement. The Annals of Thoracic Surgery, 88, 1209-1215. http://dx.doi.org/10.1016/j.athoracsur.2009.06.034

[8] Hwang, H.Y., Chang, H.W., Jeong, D.S. and Ahn, H. (2013) De Vega Annuloplasty for Functional Tricupsid Regurgitation: Concept of Tricuspid Valve Orifice Index to Optimize Tricuspid Valve Annular Reduction. Journal of Korean Medical Science, 28, 1756-1761. http://dx.doi.org/10.3346/jkms.2013.28.12.1756

[9] Minale, C., Lambertz, H. and Messmer, B.J. (1987) New Developments for Reconstruction of the Tricuspid Valve. The Journal of Thoracic and Cardiovascular Surgery, 94, 626-631.

[10] Simon, R., Oelert, H., Borst, H.G. and Lichtlen, P.R. (1980) Influence of Mitral Valve Surgery on Tricuspid Incompetence Concomitant with Mitral Valve Disease. Circulation, 62, I152-I157.

[11] Bernal, J.M., Morales, D., Revuelta, C., Llorca, J., Gutierrez-Morlote, J. and Revuelta, J.M. (2005) Reoperations after Tricuspid Valve Repair. The Journal of Thoracic and Cardiovascular Surgery, 130, 498-503. http://dx.doi.org/10.1016/j.jtcvs.2004.12.044

[12] Poveda, J.J., Bernal, J.M., Matorras, P., Hernando, J.P., Oliva, M.J., Ochoteco, A. and Berrazueta, J.R. (1996) Tricuspid Valve Replacement in Rheumatic Disease: Preoperative Predictors of Hospital Mortality. Journal of Heart Valve Disease, 5, 26-30.

[13] Al-Ebrahim, K.E. (2010) Tricuspid Valve Replacement Is an Unfavorable Operation. Letter to the Editor. European Journal of Cardio-Thoracic Surgery, 38, 115. http://dx.doi.org/10.1016/j.ejcts.2010.01.019

[14] McCarthy, P.M., Bhudia, S.K., Rajeswaran, J., Hoercher, K.J., Lytle, B.W., Cosgrove, D.M. and Blackstone, E.H. (2004) Tricuspid Valve Repair: Durability and Risk Factors for Failure. Journal of Thoracic and Cardiovascular Surgery, 127, 674-685. http://dx.doi.org/10.1016/j.jtcvs.2003.11.019

[15] Khorsandia, M., Banerjeeb, A., Singhb, H. and Srivastava, A.R. (2012) Is a Tricuspid Annuloplasty Ring Significantly Better than a De Vega's Annuloplasty Stitch When Repairing Severe Tricuspid Regurgitation? Interactive CardioVasc Thoracic Surgery, 15, 129-135. http://dx.doi.org/10.1093/icvts/ivs070

[16] Tang, G.H., David, T.E., Singh, S.K., Maganti, M.D., Armstrong, S. and Borger, M.A. (2006) Tricuspid Valve Repair with an Annuloplasty Ring Results in Improved Long-Term Outcomes. Circulation, 114, I-577-I-581. http://dx.doi.org/10.1161/CIRCULATIONAHA.105.001263

[17] Al-Ebrahim, K. and Alassal, A. (2010) Autologous Pericardial Strip Repair of the Tricuspid Valve. Annals of Thoracic Surgery, 89, 674. http://dx.doi.org/10.1016/j.athoracsur.2009.06.107

[18] Bernal, J.M., Gutiérrez-Morlote, J., Llorca, J., San José, J.M., Morales, D. and Revuelta, J.M. (2004) Tricuspid Valve Repair: An Old Disease, a Modern Experience. Annals of Thoracic Surgery, 78, 2069-2074.

http://dx.doi.org/10.1016/j.athoracsur.2004.06.067 
Scientific Research Publishing (SCIRP) is one of the largest Open Access journal publishers. It is currently publishing more than 200 open access, online, peer-reviewed journals covering a wide range of academic disciplines. SCIRP serves the worldwide academic communities and contributes to the progress and application of science with its publication.

Other selected journals from SCIRP are listed as below. Submit your manuscript to us via either submit@scirp.org or Online Submission Portal.
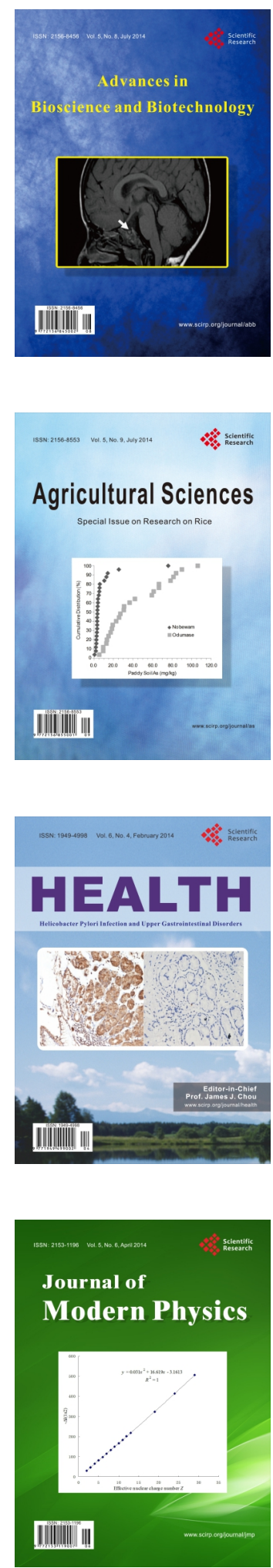
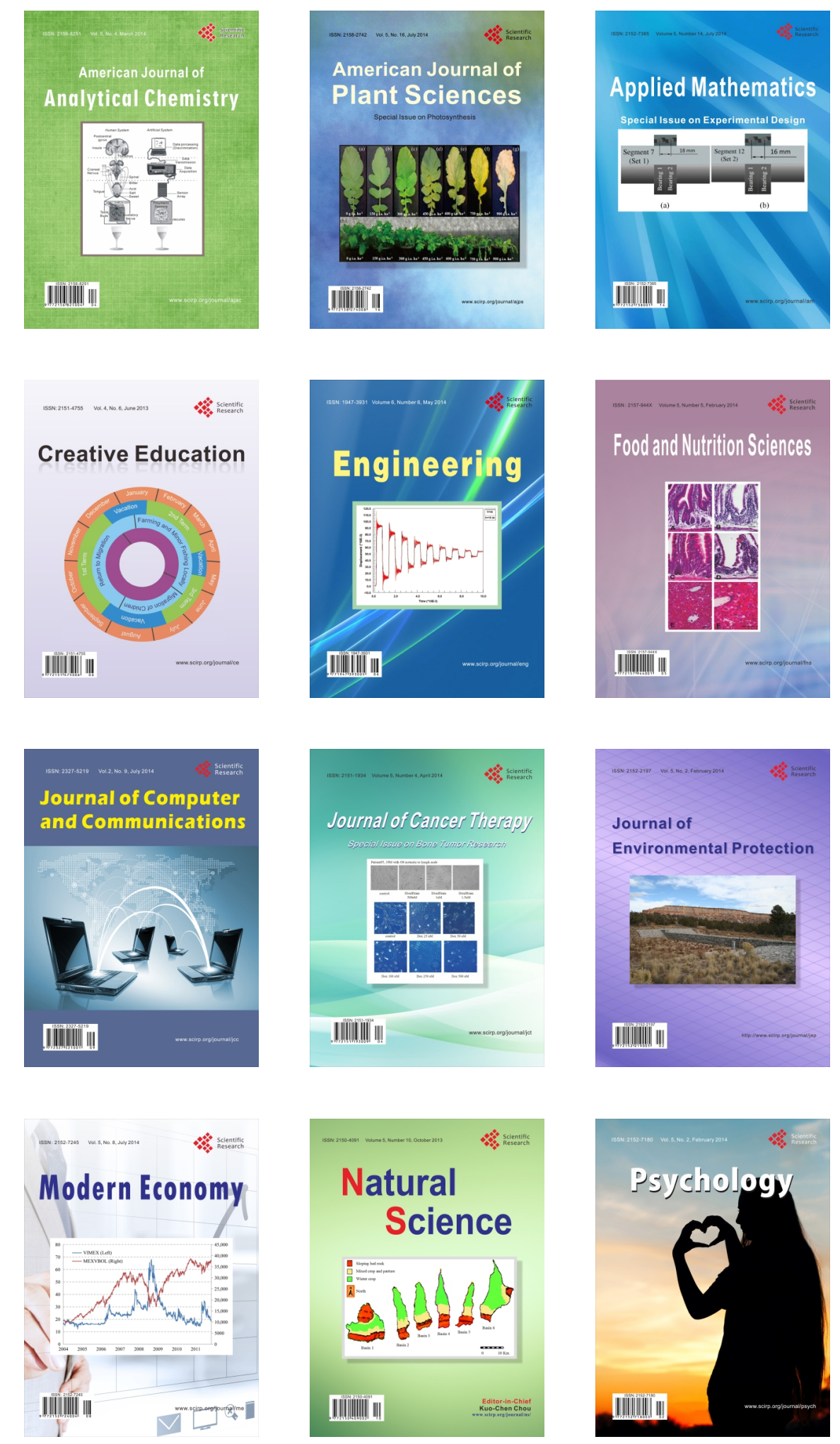